\title{
Optimal design for adiabatic pipes using vacuum at cryogenic temperatures
}

\author{
Jae-Hoon Lee ${ }^{1}$, Si-Pom Kim ${ }^{2, *}$, Rock-Won Jeon ${ }^{3}$ \\ 1, 2, 3 Department of Mechanical Engineering, Dong-A University,Hadan 2-dong, Saha-gu, Busan, \\ Korea
}

\section{Index Terms}

Vacuum Insulated Pipe

Numerical Analysis

Boil off Gas

Optimal Design

Experimental Design Method

Thermal-Structural Coupled

Field Analysis

Received: 19 October 2014

Accepted: 20 July 2015

Published: 22 Februarv 2016

\begin{abstract}
Various studies are being conducted recently on land piping for supplying and carrying cryogenic (-1630 $)$ LNG to ships. In transportation through land piping, however, the problem of BOG (Boil Off Gas) happens frequently due to difficulty in insulating the outside of the pipe. One of the methods for minimizing the occurrence of BOG is using double pipe in piping. However, research has not been made enough to minimize heat loss by inserting an insulator with high insulation performance inside the double pipe and vacuum. Thus, in planning vacuum insulated piping, this study selected the optimal combination of design factors for vacuum insulated piping using experimental design among optimal design techniques. In addition, numerical analysis was conducted to test the combination of design factors, and the results are expected to provide basic information for vacuum insulated piping design.
\end{abstract}

(c) 2016 TAF Publishing. All rights reserved.

\section{INTRODUCTION}

In recent worldwide energy generation and demand, there has been a trend of increasing need for natural gas over oil, with various studies conducted on the supply and transfer of liquefied natural gas (LNG) as a result of this tendency [1]. LNG is transported through pipelines in its liquefied state at a temperature of $-163^{\circ} \mathrm{C}$, and in this process, insulation at the exterior of the pipeline frequently generates boil-off gas (BOG). There are several methods, such as vacuum, multi-layer, and evacuated powder insulations, to minimize this BOG [2]. The vacuum insulation method is a generic term for cutting off conduction and convection using a rarefied gas, and

\footnotetext{
*Corresponding author: Si-Pom Kim

E-mail: spkim@dau.ac.kr
}

studies are being actively conducted on this topic [3]. In particular, this method is usually applied to pipelines in designing double pipes. Vacuum insulation refers to the method of reducing BOG by minimizing heat loss to the exterior through a vacuum operation after inserting a high-performance insulator into the interior of the double pipe. However, despite of demonstrating a high performance in insulation, there has been insufficient research on Vacuum-Insulated Piping (VIP) used in double pipes with insulation insertion and vacuum operation [4]. There are several major design parameters that influence heat transfer in VIP, including the degree of vacuum, insulation material, number of insulation layers, and insulator density (number of layers per unit length). However, there has been no clear presentation of fundamental data or research on these topics [5]. 


\begin{tabular}{ccccc}
\hline \hline & Control factor & \multicolumn{3}{c}{ Level } \\
\hline A & Type & 1 & 2 & - \\
B & Thickness of inner pipe & 1 & 2 & 3 \\
C & Thickness of outer pipe & 1 & 2 & 3 \\
D & Length of pipe & 1 & 2 & 3 \\
E & Roughness of inner pipe & 1 & 2 & 3 \\
F & Roughness of outer pipe & 1 & 2 & 3 \\
G & Emissivity of insulating materials & 1 & 2 & 3 \\
H & Emissivity of pipe & 1 & 2 & 3 \\
\hline \hline
\end{tabular}

Consequently, in this study, to design a vacuum-insulated pipeline, we selected a combination of optimal design parameters using the experimental design method. We also simultaneously performed numerical analysis to verify the design parameter combinations [6]. We intend to provide the results as baseline data for the design of VIP [7].

\section{DESIGN OF EXPERIMENTS}

Basic design factors were selected by using experimental design, which is one kind of design optimization method, and significant design variables were selected by using an orthogonal array.

For the experimental design, the number of control factors was set to eight, and the number of levels for each factor was set to three, resulting in the formation of an L18 orthogonal array. This method reduced the number of required experiments from a total of $2 \times 37=4374$ to 18 , allowing us to deduct the optimal factor from just those 18 . Consequently, Analysis Of Variance (ANOVA) was conducted based on experimental design, and the optimal level was determined following calculation of each factor's level of contribution. Table 1 presents the control factors and levels.

Analysis results were reviewed using experimental design. They showed that control factors A, B, and C had significant differences for each level, but not in terms of other aspects. In other words, the factors that influence heat transfer in VIP are thought to be the piping's type, inner diameter, and pipe thickness. The optimal levels deducted based on this assumption are combinations of A2, B3, C3, D3, E1, F1, G1, and H2.
TABLE 1

CONTROL FACTORS AND LEVELS

※Type 1: Bellows, Type 2: Joint

\section{NUMERICAL ANALYSIS}

\section{A. Finite Element Model}

Through experimental design, we performed numerical analysis on variations in the piping's type, inner diameter, and pipe thickness-the factors that influence heat transfer. The commercial program ANSYS v14.0 was used for numerical analysis. The finite element model used in the analysis is shown in Fig. 1. The dual insulated piping in the figure was simplified into $1 / 16$ of the model to reduce the time needed for numerical analysis.

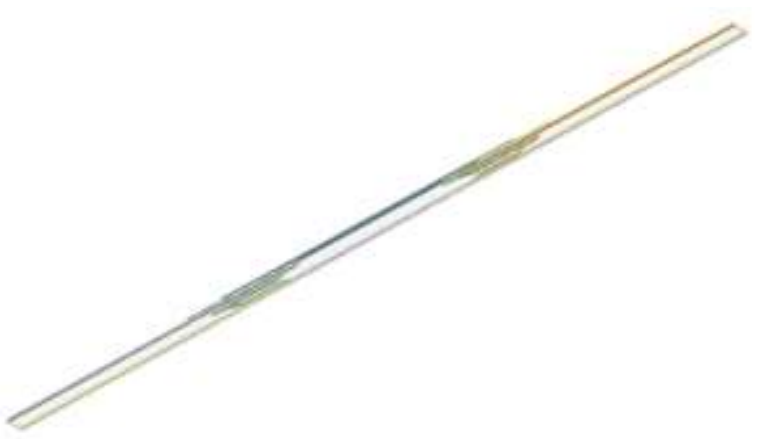

Fig. 1. Finite element model

\section{B. Thermal Analysis}

In this study, thermal analysis was conducted to examine the heat loss during the operation of the dual insulated pipe currently used in LNG transportation pipelines on land. The boundary conditions required for this analysis are shown in Table 2.

TABLE 2

THERMAL ANALYSIS BOUNDARY CONDITIONS

\begin{tabular}{lc} 
Internal temperature of inner pipe $\left({ }^{\circ} \mathrm{C}\right)$ & -170 \\
External temperature of outer pipe $\left({ }^{\circ} \mathrm{C}\right)$ & 20 \\
Convective heat transfer coefficient & 5 \\
Steel pipe emissivity & 0.1 \\
Emissivity of outside of insulator & 0.2 \\
\hline
\end{tabular}

Because simple thermal analysis allows for the observation of only the temperature distribution in the 
dual insulated piping system, a structure stability evaluation on the piping through thermal-structural coupled-field analysis was required in order to increase the reliability of the numerical analysis results.

\section{Thermal-Structural Coupled-Field Analysis}

Thermal-structural coupled-field analysis was performed by applying the temperature distribution acquired from thermal analysis. The analysis was also used as a method to increase the reliability of the results in the actual structure stability evaluation of the dual insulated piping. In the thermal-structural coupled-field analysis previously conducted by applying the temperature distribution obtained from thermal analysis, the boundary conditions were set to forced displacement constraints at both ends of the dual insulated piping. 320 bar was applied as the internal load condition. The other boundary conditions used in the thermal-structural analysis are listed in Table 3.

TABLE 3

BOUNDARY CONDITIONS USED FOR THERMALSTRUCTURAL COUPLED-FIELD ANALYSIS

\begin{tabular}{lc}
\hline \hline Inner pipe pressure & $320 \mathrm{bar}$ \\
Vacuum pressure & $10^{-3}$ Torr $(-6.6661 \mathrm{e}-7 \mathrm{MPa})$ \\
Fixed portion & Remote symmetry plane \\
\hline \hline
\end{tabular}

\section{NUMERICAL ANALYSIS RESULTS}

\section{Thermal Analysis Results}

Thermal analysis was used to find the temperature distribution and quantity of heat penetration into the dual insulated piping. Fig. 2 shows the temperature distribution with respect to variations in the pipe's diameter.

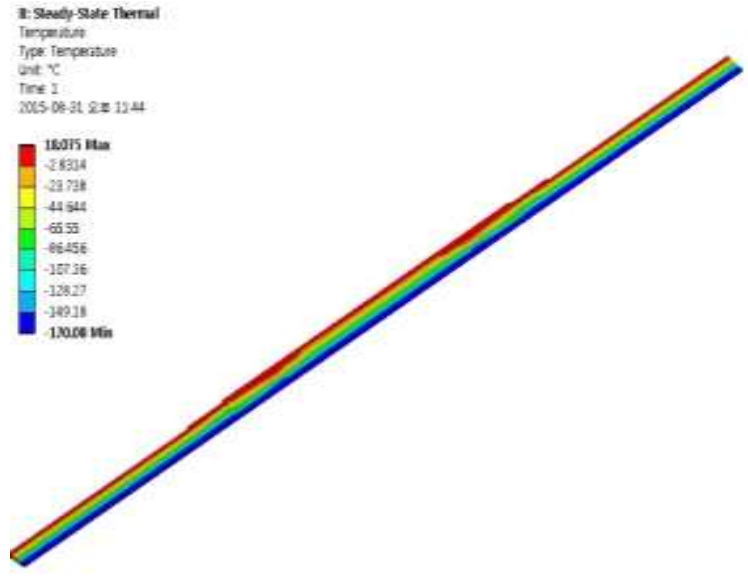

(a) 15A Dual Insulated Piping

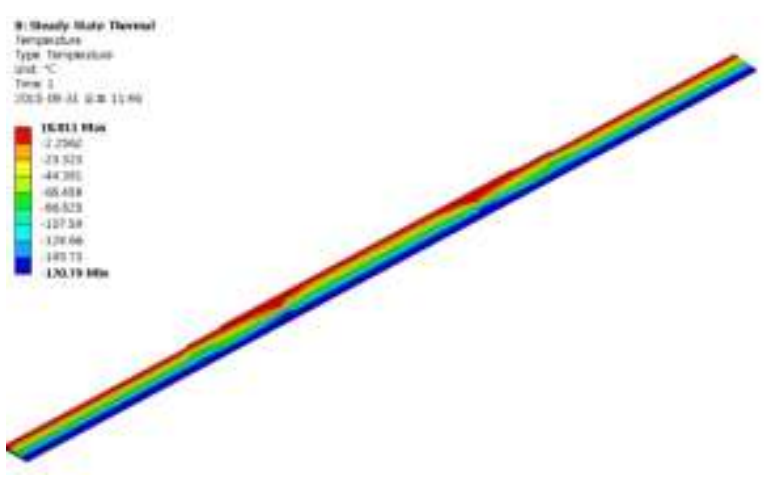

(b) 25A Dual Insulated Piping

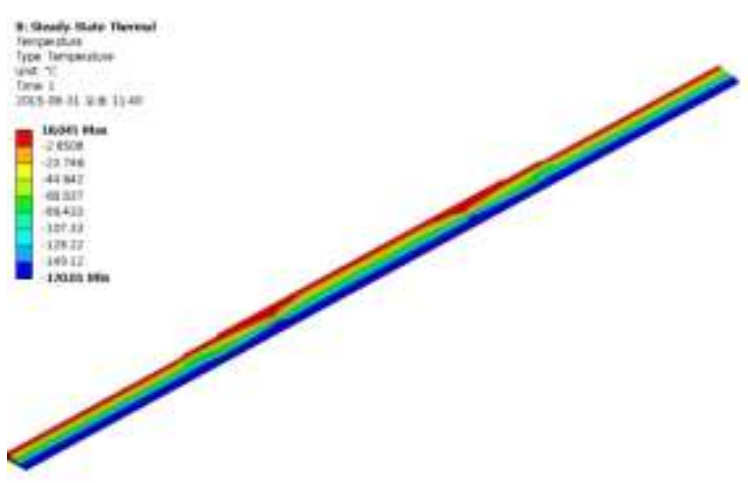

(c) 40A Dual Insulated Piping

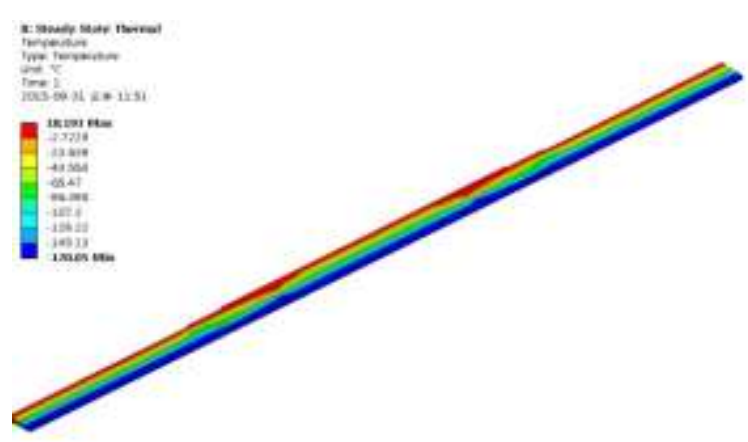

(d) 50A Dual Insulated Piping 
Fig. 2. Temperature distributions with respect to diameter variations.

The temperature distribution was found in order to compute the quantity of heat penetration into the pipe. The values obtained are shown in Fig. 3. Calculations of heat penetration using temperature distribution showed that for an increase in the dual insulated pipe's diameter, there is a decrease in heat penetration from the outside to the inside. In particular, we found that the change from the smallest pipe, $15 \mathrm{~A}$, to $25 \mathrm{~A}$ resulted in the greatest decrease in heat penetration, and we believe that variations in heat penetration are greater for shorter pipe diameters.

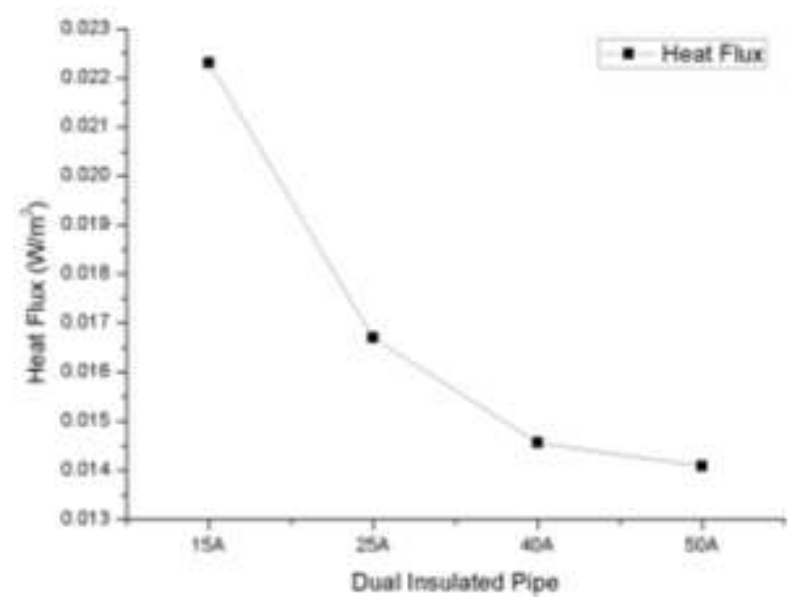

Fig. 3. Calculated heat penetration with respect to the dual insulated pipe diameter.

\section{E. Thermal-Structural Coupled-Field Analysis Results}

In the analysis of dual insulated piping, variations in the stress and deformation inside the pipe cannot be neglected in structure stability evaluation using simple thermal analysis. Thus, thermal-structural coupled-field analysis was performed based on thermal analysis results. The thermal-structural coupled-field analysis was used to increase the reliability of the numerical analysis results. The stress and deformation variations for each pipe size are shown in Fig. 4.

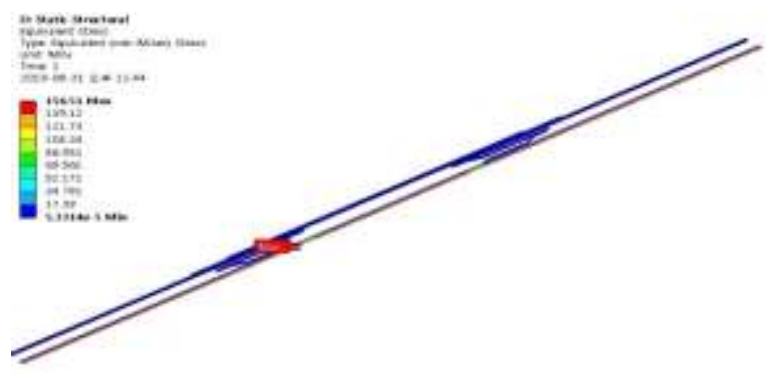

(a) 15A Generated Stress

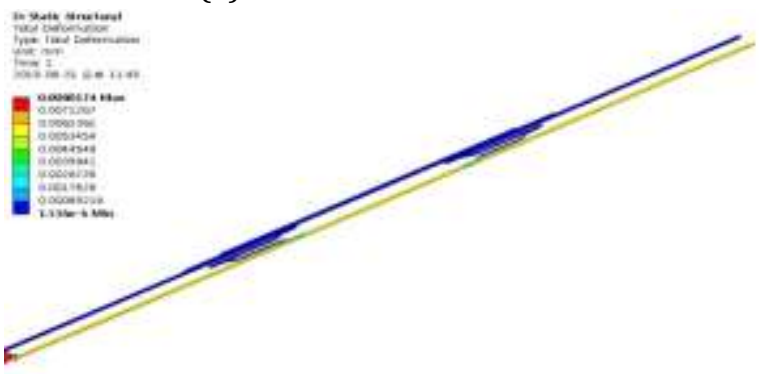

(b) 15A Deformation Variations

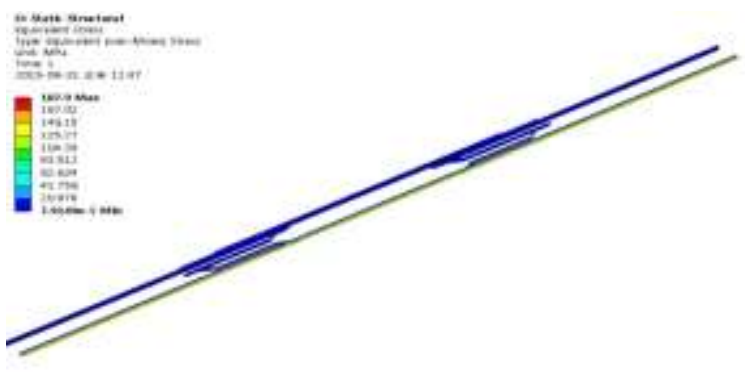

(c) $25 \mathrm{~A}$ Generated Stress

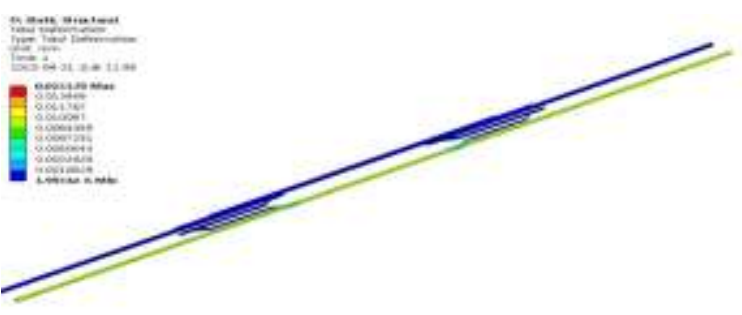

(d) 25A Deformation Variations

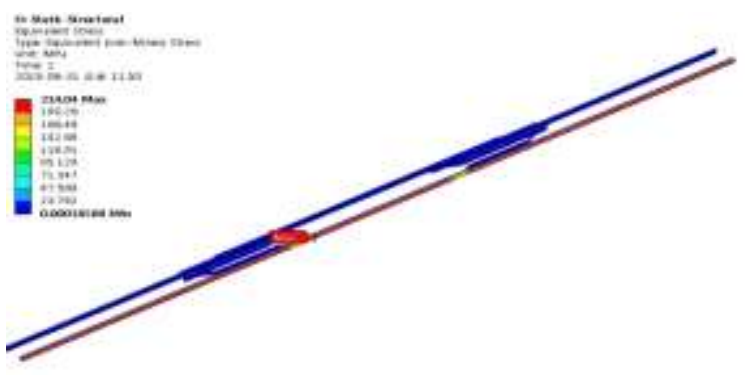

(e) 40A Generated Stress

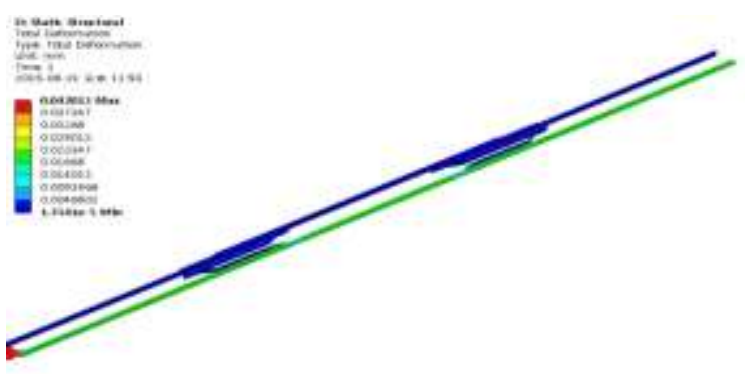

(f) 40A Deformation Variations 


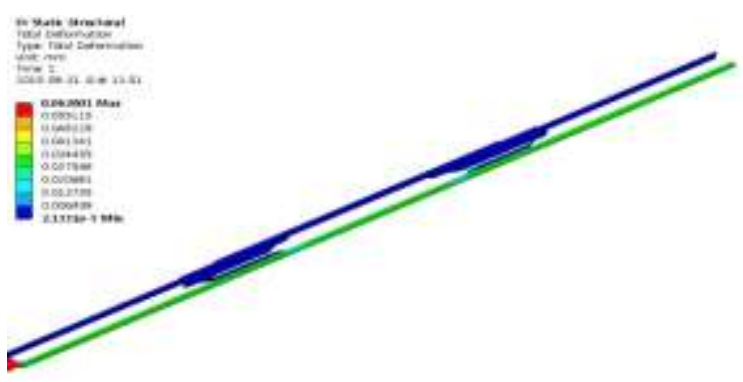

(g) 50A Generated Stress

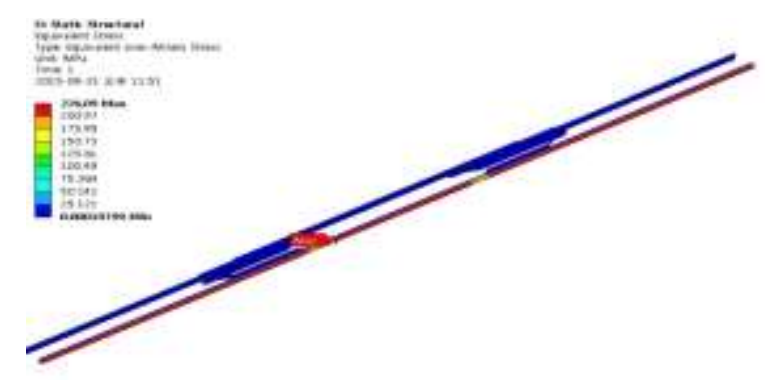

(h) 50A Deformation Variations

Fig. 4. Generated stress and deformation variations for each dual insulated pipe diameter.

The maximum stress and deformation obtained from the thermal-structural coupled-field analysis are shown in Fig. 5. The results show that the maximum stress occurs for the maximum pipe diameter, with changes in deformation having the same tendency. This result shows that stress and deformation changes increase with increasing pipe diameters, but the stress generated is $227 \mathrm{MPa}$, which is lower than the allowable stress of SUS304, the VIP material. Therefore, we believe that it is structurally safe. In addition, the variations in deformation are under 0.1 $\mathrm{mm}$; consequently, we believe they can be neglected.

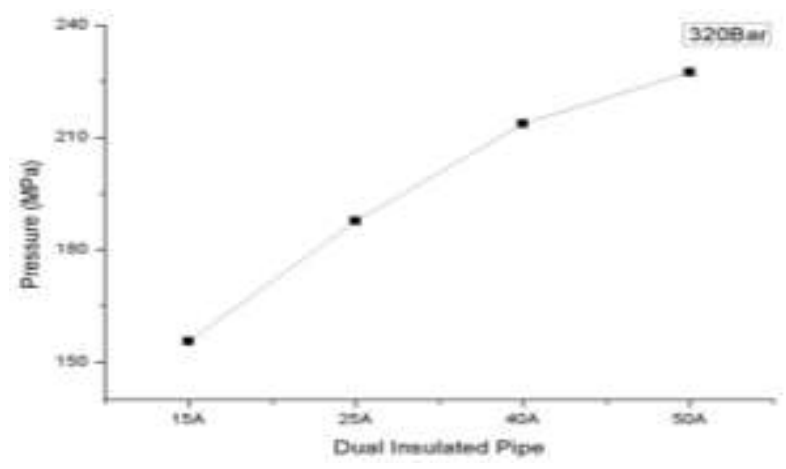

(a) Stress variation

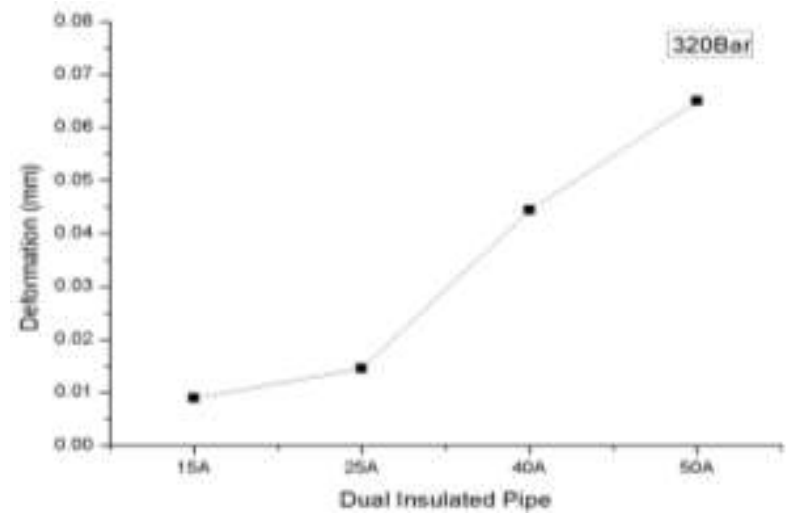

(b) Deformation variation

Fig. 5. Stress and deformation variations with respect to thermal-structural coupled-field analysis

\section{v. CONCLUSION}

In this study, experimental design was used to deduct factors for BOG reduction of the dual insulated piping used in LNG transportation. The deducted factors were used in structural stability evaluation on the dual insulated piping. Thermal-structural coupled-field analysis results required for this evaluation led to the following conclusions:

(1) The results of the analysis based on experimental design show that control factors A, B, and C are largely influential. In other words, it can be said that the piping's type, inner diameter, and thickness are the factors that influence heat transfer in VIP. Therefore, the optimal combinations of design variables are A2, B3, C3, D3, E1, F1, G1, and $\mathrm{H} 2$.

(2) Thermal analysis results show that heat penetration from the exterior to the interior decreases as the dual insulated pipe's diameter increases, and that the quantity of heat penetration changes considerably as the diameter decreases. These results indicate that pipes with small diameters require more caution in setting conditions when designing dual insulated piping, taking into account the quantity of heat penetration.

(3) Thermal-structural coupled-field analysis results show that the maximum stress and deformation tend to increase with increasing pipe diameter. However, the maximum stress is lower than the material's allowable stress. Consequently, we can assert that it is structurally safe. Further, we believe that subsequent dual insulated piping design must be accompanied by a structure stability evaluation appropriate for service conditions.

(4) We found that in the deduction of factors using experimental design, the types of pipes are also a significant factor, but this study applied only to the effect of the pipe's diameter. Therefore, we believe that there will be need for research in the future on the effect of types of 
dual insulated piping, using this paper as a reference.

\section{ACKNOWLEDGEMENT}

This work was supported by the KEIT(Korea Evaluation Institute of Industrial Technology) which is the industrial innovation program (No. 2014-0712).

\section{REFERENCES}

[1] M. E. Kim and Y. T. Kim, "The BOG handling system for LNG carrier," Korean Society Fluid Machinery, vol. 12, pp. 557-561, 2005.

[2] H. Y. Kim and B. H. Kang, "Thermal insulation technology for cryogenic cooling devices," Journal of the Korean Society of Precision Engineering, vol. 19, no. 11, pp. 24-30, 2002.

[3] D. S. Lee, "A developing tendency of liquefied natural gas carriers," Journal of the Korean Society of Marine Environment and Safety, vol. 15, no. 3, pp. 269-274, 2009.
[4] S. P. Kim, K. H. Lee, R. W. Jeon and T. W. Do, "A study on the heat flow change of vacuum jacket valve according to pressure change and jacket thickness," Journal of the Korean Society of Marine Engineering, vol. 35, no. 2, pp. 232-237, 2011.

DOI: $10.5916 /$ jkosme.2011.35.2.232

[5] J. R. Cho, D. J. Choi and H. I. Lim, "Development of cryogenic liquid valves with vacuum insulation," Journal of the Korean Society of Marine Engineering, vol. 10, pp. 297-297, 2012.

[6] J. M. Chae, Y. C. Kim and C. M. Kim, "Experimental study for vacuum-multi layer insulation performance of cryogenic vessel, The Korean Institute of Gas, vol. 11, 2008, pp. 278-283.

[7] D. H. Wi, W. Lin and M. S. Ha, "Evaluation of the structural stability of blind flange valve on low temperature environment," Joutnal of the Korean Society of Manufacturing Process Engineers, pp. 194197, 2008.

— This article does not have any appendix. - 